\title{
Treatment strategies in patients with diabetes and three-vessel coronary disease: What should we choose?
}

\author{
Bo Liang ${ }^{1}(0)$ and Ning Gu ${ }^{2^{*}}$ (D)
}

\begin{abstract}
The recent study demonstrating that percutaneous coronary intervention and coronary artery bypass grafting were associated with a lower risk of death and major adverse cardiac and cerebrovascular events (composite of all-cause death, myocardial infarction, or stroke) than with medical therapy among patients with diabetes and triple-vessel disease was very interesting. However, the nature of single-center nonrandomized and nonblinded studies that are not placebo controlled limits the extrapolation and generalizability of the results. As a result, the existing body of evidence does not fully support the use of revascularization treatment strategies in patients with diabetes and triplevessel disease. Importantly, the safety of revascularization treatment strategies in this particular population remains uncertain. Therefore, further studies are needed to assess the risks and benefits of comprehensive treatment in these patients.
\end{abstract}

As an independent risk factor for cardiovascular disease, diabetes greatly increases the incidence and mortality of cardiovascular disease [1-3]. Simultaneously, patients with diabetes are at increased risk of having a cardiovascular event and are more likely to have diffuse and multivessel vascular lesions $[4,5]$, making coronary revascularization challenging [6]. Such patients are prone to a more rapid progression of atherosclerosis, significantly increasing the need for myocardial revascularization.

The present Commentary refers to the recently published article by Zhao et al. [7] describing that, in patients with diabetes and triple-vessel disease (TVD), percutaneous coronary intervention (PCI) and coronary artery bypass grafting (CABG) were associated with a lower risk of death and major adverse cardiac and cerebrovascular events (MACCE, composite of all-cause death, myocardial infarction, or stroke) than medical therapy (MT).

\footnotetext{
*Correspondence: guning@njucm.edu.cn; jsguning@163.com

${ }^{2}$ Nanjing Hospital of Chinese Medicine Affiliated to Nanjing University of Chinese Medicine, Nanjing, China

Full list of author information is available at the end of the article
}

The authors conducted a prospective and single-center study that included 3117 patients with diabetes and TVD (defined as angiographic stenosis of $\geq 50 \%$ in all three main epicardial coronary arteries, with or without left main artery involvement) from Fuwai Hospital (Beijing, China) with a median follow-up of 6.3 years to explore whether MT or surgical treatment strategies (PCI and CABG) are the most beneficial in this special population. First, it should be noted that at baseline, before all patients received the corresponding treatment, some susceptibility factors (age, sex, peripheral arterial disease history, CABG history, revascularization history, creatinine clearance, left ventricular ejection fraction, and synergy between percutaneous coronary intervention with taxus and cardiac surgery (SYNTAX) score) were not balanced between the patients in the different groups. We all know that in real-world studies, especially singlecenter studies, baseline inequality is a common thing [8]; accordingly, we need to be careful when extending the conclusions to all populations. We are looking forward to a multicenter, prospective, randomized controlled trial to verify these findings. Second, fortunately, the

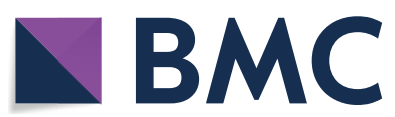

(c) The Author(s) 2021. This article is licensed under a Creative Commons Attribution 4.0 International License, which permits use, sharing, adaptation, distribution and reproduction in any medium or format, as long as you give appropriate credit to the original author(s) and the source, provide a link to the Creative Commons licence, and indicate if changes were made. The images or other third party material in this article are included in the article's Creative Commons licence, unless indicated otherwise in a credit line to the material. If material is not included in the article's Creative Commons licence and your intended use is not permitted by statutory regulation or exceeds the permitted use, you will need to obtain permission directly from the copyright holder. To view a copy of this licence, visit http://creativeco mmons.org/licenses/by/4.0/. The Creative Commons Public Domain Dedication waiver (http://creativecommons.org/publicdomain/ zero/1.0/) applies to the data made available in this article, unless otherwise stated in a credit line to the data. 
authors performed a detailed subgroup analysis for different SYNTAX scores, and the results showed that when all-cause death was the clinical endpoint, regardless of the SYNTAX subgroups, patients in the PCI and CABG groups showed a significantly lower risk than those in the MT group. However, when MACCE was the clinical endpoint, PCI failed to reduce the risk of MACCE compared with MT $(P=0.559)$ in patients with a SYNTAX score of $\leq 22$. Third, in this population, it may be difficult to choose the optimal revascularization strategy. The outcomes of CABG or PCI have been extensively evaluated. The authors found that the risk of death in the PCI group (HR 0.40, 95\% CI 0.32 0.51, $P<0.0001$ ) and the CABG group (HR $0.33,95 \% \mathrm{CI} 0.26 \sim 0.44, P<0.0001$ ) was significantly lower than that in the MT group, while the CABG group had a lower risk of death compared with the PCI group with no significant difference (HR 0.83, 95\% CI 0.62 1.18, $P=0.2215$ ); the risk of MACCE in the PCI group (HR0.71, 95\% CI $0.60 \sim 0.84, P<0.0001$ ) and the CABG group (HR 0.48, 95\% CI0.39 0.57, $P<0.0001$ ) was significantly lower than that in the MT group, while the CABG group had a lower risk of MACCE compared with the PCI group (HR0.67, 95\% CI0.55 0.81, $P<0.0001$ ), which are not consistent with our conclusions that CABG group has lower all-cause mortality, cardiac mortality, recurrent myocardial infarction, and repeat revascularization and higher cerebrovascular accident than the PCI group by integrating 6 randomized controlled trials (ARTS, BARI 2D, FERRDOM/FERRDOM Follow-On, MASS II, SYNTAX, and VACARDS). Finally, the authors focus on the effectiveness but ignore the safety. Safety is also a very important factor to consider when clinicians make decisions.

In summary, the results presented in the existing body of evidence do not fully support the use of revascularization treatment strategies in patients with diabetes and TVD. Importantly, the safety of revascularization treatment strategies in this particular population remains uncertain. Therefore, further studies are needed to assess the risks and benefits of comprehensive treatment in those patients.

\footnotetext{
Abbreviations

CABG: Coronary artery bypass grafting; MACCE: Major adverse cardiac and cerebrovascular events; MT: Medical therapy; PCl: Percutaneous coronary intervention; SYNTAX: Synergy between percutaneous coronary intervention with taxus and cardiac surgery; TVD: Triple-vessel disease.
}

\section{Acknowledgements}

We thank all scientists and participants involved in diabetes and three-vessel coronary disease.

\section{Authors' contributions}

BL and NG conceived, designed, or planned the commentary. All authors collected and read the literature. BL drafted the manuscript. NG revised the manuscript. Both authors read and approved the final manuscript.

Funding

None.

Availability of data and materials

Not applicable.

Ethics approval and consent to participate

Not applicable.

Consent for publication

Not applicable.

Competing interests

The authors declare that they have no competing interests.

\section{Author details}

${ }^{1}$ Nanjing University of Chinese Medicine, Nanjing, China. ${ }^{2}$ Nanjing Hospital of Chinese Medicine Affiliated to Nanjing University of Chinese Medicine, Nanjing, China.

Received: 26 January 2021 Accepted: 6 February 2021

Published online: 11 February 2021

\section{References}

1. Wong Y-K, Cheung CYY, Tang CS, Hai JSH, Lee C-H, Lau K-K, Au K-W, Cheung BMY, Sham P-C, Xu A, et al. High-sensitivity troponin I and B-type natriuretic peptide biomarkers for prediction of cardiovascular events in patients with coronary artery disease with and without diabetes mellitus. Cardiovasc Diabetol. 2019;18(1):171.

2. Guo L, Wang J, Ding H, Meng S, Zhang X, Lv H, Zhong L, Wu J, Xu J, Zhou $X$, et al. Long-term outcomes of medical therapy versus successful recanalisation for coronary chronic total occlusions in patients with and without type 2 diabetes mellitus. Cardiovasc Diabetol. 2020;19(1):100.

3. Ram E, Sternik L, Klempfner R, lakobishvili Z, Fisman EZ, Tenenbaum A, Zuroff E, Peled Y, Raanani E. Type 2 diabetes mellitus increases the mortality risk after acute coronary syndrome treated with coronary artery bypass surgery. Cardiovasc Diabetol. 2020;19(1):86.

4. Dai X, Luo Z-C, Zhai L, Zhao W-P, Huang F. Reassessing coronary artery bypass surgery versus percutaneous coronary intervention in patients with type 2 diabetes mellitus: a brief updated analytical report (20152017). Diabetes Ther 2018:9(5):2163-71.

5. Kogan A, Ram E, Levin S, Fisman EZ, Tenenbaum A, Raanani E, Sternik L. Impact of type 2 diabetes mellitus on short- and long-term mortality after coronary artery bypass surgery. Cardiovasc Diabetol. 2018;17(1):151 .

6. Godoy LC, Ko DT, Rao V, Farkouh ME. The role of coronary artery bypass surgery versus percutaneous intervention in patients with diabetes and coronary artery disease. Prog Cardiovasc Dis. 2019;62(4):358-63.

7. Zhao X, Xu L, Jiang L, Tian J, Zhang Y, Wang D, Sun K, Xu B, Zhao W, Hui R, et al. Real-world outcomes of different treatment strategies in patients with diabetes and three-vessel coronary disease: a mean follow-up 6.3 years study from China. Cardiovasc Diabetol. 2021;20(1):16.

8. Liang B, Zou F-H, Fu L, Liao H-L. Chinese herbal medicine Dingji Fumai decoction for ventricular premature contraction: a real-world trial. BioMed Res Int. 2020;2020:5358467.

\section{Publisher's Note}

Springer Nature remains neutral with regard to jurisdictional claims in published maps and institutional affiliations. 